\title{
The Role Definition and Competency Model Building of the Teaching Assistant of the MOOCS
}

\author{
Wang Dongmei ${ }^{l}$,Yang Liyuan ${ }^{l}$,Zhang Xiaohui ${ }^{2}$ \\ ${ }^{1}$ School of Distance and Continuing Education ,Dalian University of Technology, Dalian, China \\ ${ }^{2}$ School of Computer and Information Technology, Liaoning Normal University, Dalian, China
}

\begin{abstract}
The teaching assistant has been the key element of the MOOCS. Their competence and ability affect the study support service quality of the MOOCS. Based on the connotation and function of the teaching assistant defined, combining the onion competence model theory and the study of relevant literature at home and abroad, this paper constructs the role and competency model of the teaching assistant of MOOCS, and explores the model application in the construction of teacher staff, in order to make effort to provide support for China's MOOCS.
\end{abstract}

\section{Introduction}

Massive open online courses is a new type learning mode of current education. As the "giant" of scale, the "diversity" of students and the "people-oriented" of the teaching mode, MOOCS has caused extensive concern of the society[1].Teachers of MOOCS come from the top universities all over the world, which have great attraction for the learners. On the other hand, many teachers also become the "stars" through MOOCS course quickly. The "stars" have won the "word of mouth" for the colleges and universities, which in turn have greatly promoted MOOCS institutions. MOOCS, however, are lack of tutors, and without the construction of faculty development support system. MOOCS increase the influence of the course by "the school, the teacher and the class", and collaborative works of "college joined, unified platform, unified production". On the other hand, lack of effective learning support services and complete the teaching management system, MOOCS safeguards the teaching quality by the prestigious reputation of the school only[2].Therefore, determine how to perfect learning support service and teaching management system, so as to promote the development of MOOCS? First, we need to clear the requirement of the teaching assistants in the learning support services. This paper will emphasis on this, namely the responsibilities and competency of the teaching assistants of MOOCS.

\section{The connotation and function defining of the teaching assistant of the MOOCS}

The lecturer of the MOOCS will be only one or a few people, and the course cannot be done by the lecturer itself. Before the course online, a lot of curriculum resources need to be prepared, including the content of curriculum, the reference materials, assignments and exams, etc., and the course video need to be recorded and made, which are completed by the production team coordinating with each other. Then the course will be designed to be better presented on the platform. Next, the course will be tested so to complete the operation. After the course online, the technical and content support will be needed and teachers also need to grasp the curriculum situation and students' learning dynamic condition timely. So the teaching team of MOOCS 
should consists of the lecturer, the curriculum production team and the other personnel, which we call "teaching assistant". In this paper, the teaching assistants will complete all the other work except lecturer's and the curriculum production teams', including curriculum designing, curriculum testing, perfecting the course resources and providing technical support services and so on. The role sharing and functions defining of MOOCS course mode is shown in Fig.1.

\section{The theory of onion}

The quality model theory was first originated by David McClell in America in the 1970 s. As the harvard university professor, in the paper of "testing competence rather than intelligence", David McClell first proposed the concept of "quality", namely the individual condition and behaviour characteristics which impacted on the job performance. In his paper, good performance on the job depends on personality traits, motive and values, which hidden in brain, in addition to the necessary knowledge and skills with work. Mcclelland put forward a new human resource evaluation analysis technology which is named the ability competence model, the model refine the core quality and ability of the performance outstanding personnel. Based on this theory, Richard Boyatzis from American put forward the "onion competence model "[3], which show the core elements of the quality, and illustrates the characteristics of the components can be observed and measured as is shown in fig. 2.

The characteristics and motives are the core of the onion model, and then the self-image, the social roles, the attitudes and values, the knowledge and skills expanding outward in turn. The elements which are more to the outer layer, more easy to be cultivated and evaluated; and more to the inner layer, more difficult to be evaluated and acquainted.

\section{The relevant literature at home and abroad}

Retrieving with the keywords of "teaching assistants + MOOCS" and "tutors + MOOCS" from the CNKI, Chinese digital periodical group, the Google academic, the Springer Online Journals, only 3 relevant articles are found. As the work of teaching assistant is similar to the distance counselling teachers, network guide teachers, network teachers, and e - tutoring, e - facilitating, e mentoring, online teacher, online instructor. In this paper, further expanding the search scope, investigates and combs the relevant literature about the online education tutors and network guide teachers at home and abroad with the above keyword to provide the basis for subsequent research.

\subsection{The relevant literature abroad}

Combing foreign literature study (As shown in Table 1),we find foreign scholars about the quality of the teaching assistant focused on their ability, such as the teaching ability, the technology, the management and social dimension, which are get higher consensus. In addition, the ability of design, the research and evaluation dimensions are also got more mentioned.

Dimensions of the teaching ability obtained identity by all the literature, which was to provide support and guide for the students. Dimensions of the teaching ability focused on the students grasp the course content, such as the content catalysts, the processes catalysts, the solution of the problem, and to promote the students understanding of the courses, to organize and guide the learning intercourse, to answer students' questions about the course learning, and to motivate learning motivation through the teaching strategy, etc.

Ability of technology dimensions has also been mentioned in all documents, which referred to the technology integration and support capabilities of the teaching assistants, including selecting guidance technology, teaching design according to different technical environment, and technical feedback and support for the learning process. Teaching assistants don't need to be technical experts, but inform technical support for the students with difficulties.

Ability of social dimension also received high recognition. It referred to the ability of community construction and the maintenance of teaching assistants under the network. Ability of social dimension had nothing to do with students' learning tasks and learning content. It created the sense of belonging for students to 
eliminate cognitive obstacles and interference, including building positive network corporation, motivating students to participate in the network society, grasping the network community development direction and maintaining community cohesion.

The ability of management dimension is mentioned more. It referred to the ability of teaching organization and regulation of the teaching assistant. In the network autonomous learning, most learners may lack the ability to learn and self management. Therefore, an important responsibility of the assistant teaching is to organize the network learning activities and processes. So the teaching assistants must have the ability of management, in particular, guiding and controlling ability, stimulating learning motivation and enthusiasm ability, continuous attention and timely warning ability, handling teaching event ability and so on.

The ability of teaching design dimensions in the literature referred to the ability of the development and planning of teaching activities, including tutoring programming and planning online as well as the designing of resources based on the technology of interaction.

The ability of study dimensions in the literature referred to the research and innovation ability of the teaching assistant about the course guidance, including studying and providing learning strategy according to the psychological characteristics of adult learners, studying the frontier disciplines knowledge, innovation as well as promoting the open and distance education, etc.

The ability of evaluation dimension of the teaching assistant concentrated the monitoring and feedback ability which required in the tutoring work, including the teaching evaluation and demand forecast, monitoring and evaluation on the learning strategies and learning process as well as the evaluation of the inspection.

\subsection{The relevant literature at home}

The relevant literature at home about the teaching assistant mainly focused on the ability condition and role playing.

\subsubsection{From the view of ability condition}

Related the research abroad, the study at home also pointed out that the teaching assistants should possess the abilities, including teaching, evaluation, social, management, technology, design, etc.. Although every ability was mentioned individually, the views of domestic scholars are accordance with the foreign research(As is shown in Table 2).

\subsubsection{From the view of role playing}

Contrasting with the research about ability, the other domestic literature mainly discussed on the roles of teaching assistants. Jiang Yulian and Yao Wenjian [19] pointed out that an excellent teaching assistant was not only the tutor, but also the partnership, and the changer to drive the distance learning, as well as the service experts for the students' autonomous learning. Liu Ming[20] defined the teaching assistant as the navigator, the information provider of learning, the learning facilitator, and the director of the teaching goal. Ren Hong [21] indicated the teaching assistant should be the " guides" of the learning mode and the "instructor" of learning process, the " counsellor" of the learning content, as well as the "supervisor" of the learning effect and the "researcher" of the theory, Xie Qun etc. [22] pointed out that the teaching assistant may be the instructor for guiding students to effective learning, the servicer that provided circumspect support, and the researcher promoted the pen and distance education. Hu Liqiang [23] orientated the teaching assistant as twelve kinds of roles, such as the organizer of the learning process, the designers of the curriculum resources, etc..

Above the researches, this paper argues that the role of a good teaching assistant is not only a teacher to provide quality learning content and lead students to complete the task, but also a friend that observes students to learning situation and encourages students to study actively, and a support servicer provides circumspect service as well as a researcher that guarantees students to effective learning and promotes the development of remote teaching.

\section{The role and competency model building of the teaching assistant of the MOOCS teaching mode}


The teaching assistant mode of the MOOCS is built based on the onion competence model theory and the relevant literature at home and abroad. The mode is composed by three dimension, as "for the student, the role-playing and the ability demanded. As is shown in Fig. 3.

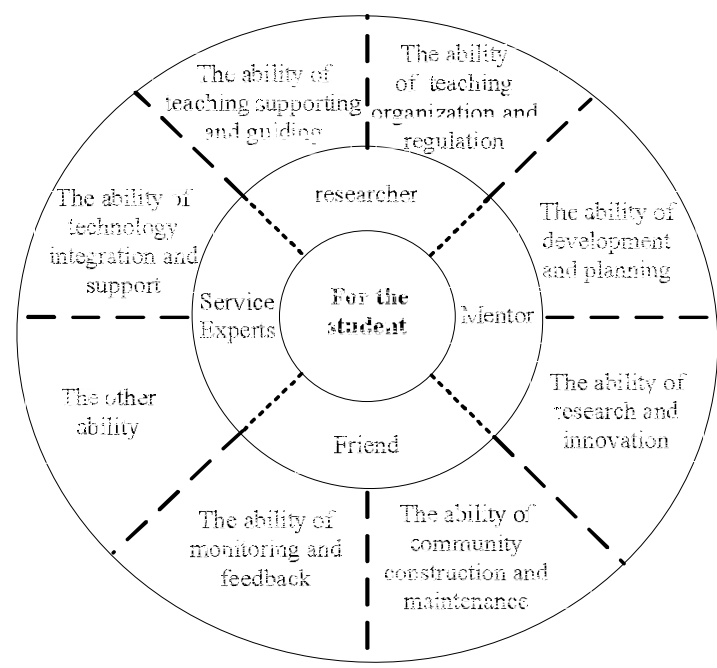

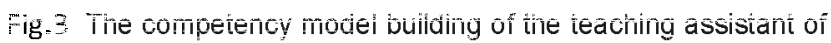
the iviơC teaching mode based on the theory of onion

"For the Student" is the power quality of the teaching assistant, which requires teaching assistant should have the service consciousness, starting with students' demand, guiding and inspiring the right motivation, cultivating the students' interest, and help them solve psychological barriers, and improve autonomous learning ability, as well as provide learning methods and strategies, etc. The dedication and service consciousness is the power personality of the teaching assistant. It embodies the personality traits of the teaching assistant unity of the internal motivation on the basis of interest and the external motivation driving by the ideal.

The role-playing constitutes with the mentors, the friends, and the service of experts and the researchers, as the social role dimensions of the teaching assistant, which is described specifically above.

The dimensions of ability demanded constitutes of the ability of teaching supporting and guiding, the ability of community construction and maintenance, the ability of technology integration and support, the ability of teaching organization and regulation, the ability of development and planning, the ability of research and innovation, the ability of monitoring and feedback , and the other ability. The other ability refers to the teaching assistants should provide students with the career and course selection consulting. The dimensions of ability demanded is the core competence of the teaching assistant, which belongs to the necessary condition for the teaching assistant.

The entire model embodies the competence factors of the teaching assistant as a professional in the sustainable and professional development. It also shows the teaching assistant should gradually from counselling daily to promoting students' effective learning, and improve the teaching support service quality and for the benign development of MOOCS. The Model clearly demonstrates the service consciousness and the social role of the teaching assistant, describes the necessary abilities to produce excellent performance of the teaching assistant, which help the teaching management system of MOOCS understand the competence level and performance improvement for the teaching assistant . on the other hand, the teaching assistant can promote their professionalism and specialization development through understanding and practical the competence model. The competence model also provides the policy basis and reference for the teaching staff construction of MOOCS in our country.

\section{References}

1. Li Man-li. Features and design principles of MOOCS. Tsinghua university education research.2013(4):13-21.

2. Yao Yuan, Han Xibin, Liu Yingqun, Cheng Jian. comparative study on the operation mechanism of MOOCS and remote education. Journal of distance education ,2013,6:3-10.

3. BOYATZIS A R. The Component Manager: A Model for Effective Performance[M].New York:John Wiley, 1982.

4. Berge, Z.L. and Collins, M.P. (Eds.) Computer Mediated Communication and the online classroom[M]. Cresskill, NJ:Hampton Press. 1995, $1-3$.

5. Shepherd, C.( 2003 ). E-learning' s greatest hits[M]. Brighton:Above and Beyond Ltd,2003. 
6. J Bawane, JM Spector.Prioritization of online instructor roles: implications for competency based teacher education programs[J]. Distance Education ,2009,30(3):383-397.

7. Banzato, M. and Constantino, G.D. Competence Based Tutoring Online. Learning to Live in the Knowledge Society[J]. IFIP International Federation for Information Processing, 2008(281):209-216.

8. Peter Goodyear, Gilly Salmon, J.Michael Spector, Christine Steeples,Sue Tickner. Competences for Online Teaching[J]. Educational Technology Research and Development, 2001, 49(1): 65-72.

9. Dennis,B.,Watland,P.,Pirotte,S.,\&Verday,N.Roleand Competencies of the E- tutor[DB/OL]. http://orbi.ulg.ac.be/bitstream/2268/12722/1/DENIS _WATLAND_PIROTTE_VERDAY_Roles_and_c ompetencies_of_the_tutor_30_03_2009.pdf,2014-0 7-05.

10. Aydin,CH.Turkish mentors,perception of roles,competencies and resources for onlie learning $[\mathrm{J}]$.Turkish Online Journal of Distance Education-TOJDE,2005,6(3):58-80.

11. Sanjaya Mishra. Roles and competencies of academic counsellors in distance education[J]. Open Learning, 2005, 20(2):147-159.

12. From the athabasca university internal information

13. Teresa Guasch, Ibis Alvarez and Anna Espasa. Roles and Domains to Teach in Online Learning Environments: Educational ICT Competency Framework for University Teachers[A]. Changing Cultures in Higher Education[C]. Heidelberg:Springer Berlin Heidelberg Inc., 2010. 339-353.
14. Li Shuang and Zhang Yanxia. An Empirical Study on the Role Defining and Functional Transform of Course Tutor of Open Universities in Online Education Era[J]. China Educational Technology,2014,(9): 50-58.

15. Huang Xun, ChenWei, Zhou Chihe. empirical research on the ability framework of Online tutoring teachers [J].Journal of Guangxi Open University,2015,(3):11-17.

16. Li shuang, Chen Li. job analysis research of key professional roles of China's remote education [J]. China Educational Technology,2008,(12) :38-43.

17. HongQingGen. research of the role and responsibilities of Online tutor $[\mathrm{J}]$. China Educational Technology,2010,(5):47-50.

18. Chen li, Feng xiaoying. research on the role ability condition of the Counseling teachers in the network [J]. China Educational Technology, 2012(7):58-63.

19. Jiang Yulian, Yao Wenjian. research on quality model building and application of the Distance education teachers $[\mathrm{J}]$. China Educational Technology.2009(12):62-65.

20. Liu Min. thinking on Teachers' role in open education teaching $[\mathrm{J}]$. Journal of adult education,2012,(7):51-52.

21. Ren Hong. the role change and relocation of the teacher in the Open University [J]. China's school education: in late,2012,(4): 68-68.

22. Xie Qun, Zhou Shaofeng, Liu Dingbang. the role evolution of the tutors of TV university course in the distance open education environment $[\mathrm{J}]$. China distance education,2003,(5):36-39.

23. Hu Liqiang. study of the role of the counseling teachers Under the distance education[J]. Journal of education research,2009,(2): 90-91. 


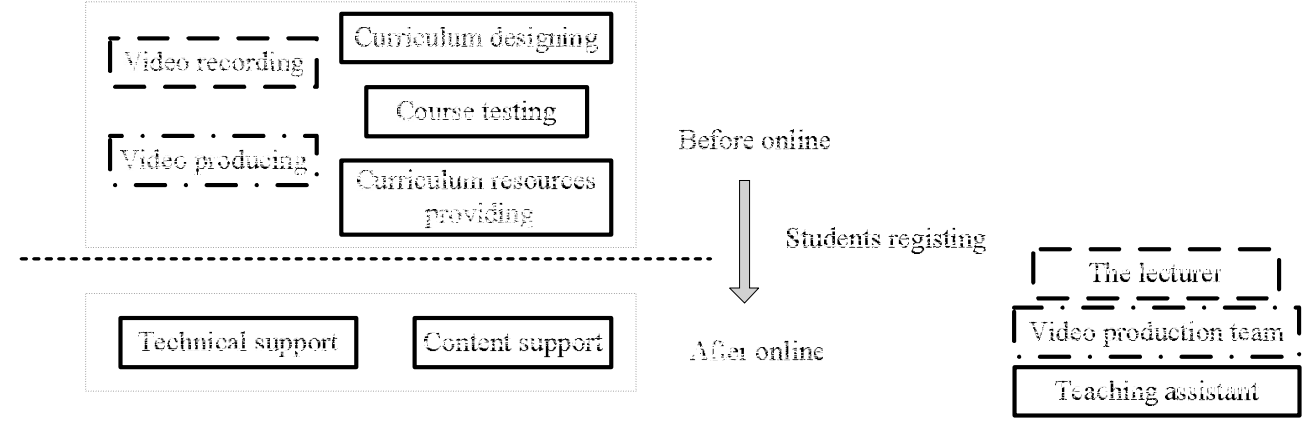

Fig. 1 Thir iole shong ard functions defining of the Mocsconse mode

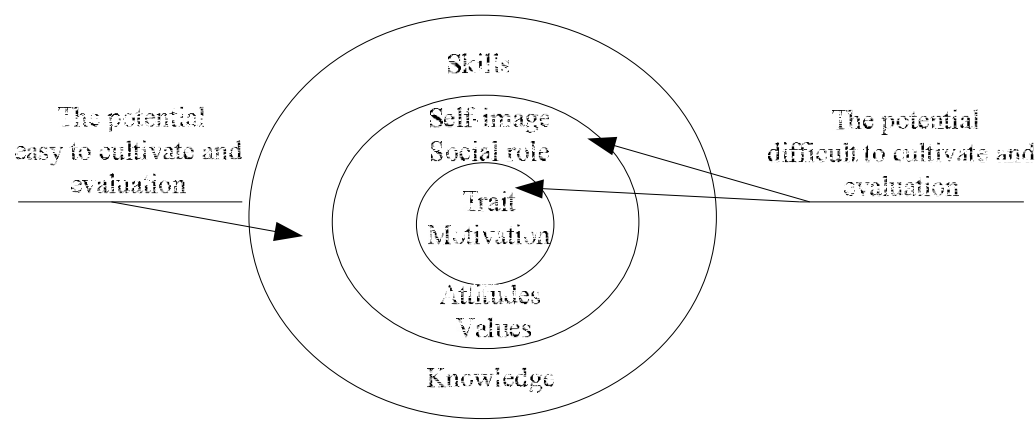

Fig 2 the minn conpente mol

Table 1. The research summary abroad about the teaching assistant competence

\begin{tabular}{|c|c|c|c|c|c|c|c|c|}
\hline $\begin{array}{c}\text { The } \\
\text { Researchers }\end{array}$ & Teaching & Technology & Social & Management & Design & Study & Evaluation & Consulting \\
\hline Berge[4] & $\sqrt{ }$ & $\sqrt{ }$ & $\sqrt{ }$ & $\sqrt{ }$ & & & & \\
\hline Shepherd[5] & $\sqrt{ }$ & $\sqrt{ }$ & & & $\sqrt{ }$ & & & \\
\hline Bawane[6] & $\sqrt{ }$ & $\sqrt{ }$ & $\sqrt{ }$ & $\sqrt{ }$ & & $\sqrt{ }$ & $\sqrt{ }$ & $\sqrt{ }$ \\
\hline Banzato[7] & $\sqrt{ }$ & $\sqrt{ }$ & $\sqrt{ }$ & $\sqrt{ }$ & $\sqrt{ }$ & $\sqrt{ }$ & & \\
\hline $\begin{array}{c}\text { Goodyear et } \\
\text { al }[8]\end{array}$ & $\sqrt{ }$ & $\sqrt{ }$ & $\sqrt{ }$ & $\sqrt{ }$ & $\sqrt{ }$ & $\sqrt{ }$ & $\sqrt{ }$ & \\
\hline Dennis[9] & $\sqrt{ }$ & $\sqrt{ }$ & $\sqrt{ }$ & $\sqrt{ }$ & $\sqrt{ }$ & $\sqrt{ }$ & $\sqrt{ }$ & \\
\hline Aydin[10] & $\sqrt{ }$ & $\sqrt{ }$ & $\sqrt{ }$ & $\sqrt{ }$ & $\sqrt{ }$ & $\sqrt{ }$ & $\sqrt{ }$ & \\
\hline Sanjaya[11] & $\sqrt{ }$ & $\sqrt{ }$ & $\sqrt{ }$ & $\sqrt{ }$ & & $\sqrt{ }$ & $\sqrt{ }$ & \\
\hline Ally[12] & $\sqrt{ }$ & $\sqrt{ }$ & $\sqrt{ }$ & $\sqrt{ }$ & & & $\sqrt{ }$ & \\
\hline Guasch[13] & $\sqrt{ }$ & $\sqrt{ }$ & $\sqrt{ }$ & $\sqrt{ }$ & $\sqrt{ }$ & & & \\
\hline Total & 10 & 10 & 9 & 9 & 6 & 6 & 6 & 1 \\
\hline
\end{tabular}

Table 2. The research summary about the teaching assistant competence at home

\begin{tabular}{|c|c|c|c|c|c|c|}
\hline The Researchers & Teaching & Evaluation & Social & Management & Technology & Design \\
\hline LiShuang and ZhangYanxia[14] & $\sqrt{ }$ & $\sqrt{ }$ & $\sqrt{ }$ & $\sqrt{ }$ & \\
\hline HuangXun[15] & $\sqrt{ }$ & $\sqrt{ }$ & & $\sqrt{ }$ & \\
\hline LiShuang and ChenLi [16] & $\sqrt{ }$ & $\sqrt{ }$ & $\sqrt{ }$ & & \\
\hline Hong Qinggen [17] & $\sqrt{ }$ & $\sqrt{ }$ & $\sqrt{ }$ & & \\
\hline Chen Liand FengXiaoying [18] & $\sqrt{ }$ & & $\sqrt{ }$ & $\sqrt{ }$ & $\sqrt{ }$ \\
\hline Total & 5 & 4 & 4 & 3 & 2 & 2 \\
\hline
\end{tabular}

